\title{
Influence of anti-filarial chemotherapy strategies on the genetic structure of Wuchereria bancrofti populations
}

\author{
Dhamodharan Ramasamy ${ }^{1}$, Hoti Sugeerappa Laxmanappa ${ }^{1 /+}$, Rohit Sharma ${ }^{1}$, Manoj Kumar Das ${ }^{2}$ \\ ${ }^{1}$ Vector Control Research Centre, Indian Council of Medical Research, Indira Nagar, Puducherry, India \\ ${ }^{2}$ National Institute of Malaria Research, Indian Council of Medical Research, Ranchi, India
}

\begin{abstract}
Lymphatic filarial (LF) parasites have been under anti-filarial drug pressure for more than half a century. Currently, annual mass drug administration (MDA) of diethylcarbamazine (DEC) or ivermectin in combination with albendazole (ALB) have been used globally to eliminate LF. Long-term chemotherapies exert significant pressure on the genetic structure of parasitic populations. We investigated the genetic variation among 210 Wuchereria bancrofti populations that were under three different chemotherapy strategies, namely MDA with DEC alone (group I, $n=74$ ), $M D A$ with DEC and ALB (group II, $n=60$ ) and selective therapy (ST) with DEC (group III, $n=34$ ) to understand the impact of these three drug regimens on the parasite genetic structure. Randomly amplified polymorphic DNA profiles were generated for the three groups of parasite populations; the gene diversity, gene flow and genetic distance values were determined and phylogenetic trees were constructed. Analysis of these parameters indicated that parasite populations under ST with a standard dose of DEC (group III) were genetically more diverse (0.2660) than parasite populations under MDA with DEC alone (group I, $H=0.2197$ ) or with DEC + ALB (group II, $H=0.2317$ ). These results indicate that the MDA may reduce the genetic diversity of $\mathrm{W}$. bancrofti populations when compared to the genetic diversity of parasite populations under ST.
\end{abstract}

Key words: Wuchereria bancrofti - chemotherapy - genetic diversity

Mass drug administration (MDA) has been used since 2000 (WHO 2002) for the elimination of lymphatic filariasis (LF), employing diethylcarbamazine (DEC) or ivermectin (IVM) in combination with albendazole (ALB). Such programmes implemented for several years may exert a strong selective pressure on parasite populations (Grant 1994), leading to the emergence of drug-resistant strains. Many studies have reported that drug pressures on parasite populations leads to the development of drug resistance and reduces genetic variation among parasite populations (Wolstenholme et al. 2004). Eberhard et al. (1991) generated evidence of resistance to DEC in Wuchereria bancrofti, which indicates the possible threat of wide-spread resistance to the commonly used antifilarial drug, DEC. Eberhard et al. (1991) also reported that $W$. bancrofti population structures were influenced by anti-filarial chemotherapy with DEC. However, there were very few studies on the influence of anti-filarial chemotherapies on the genetic structure of populations of lymphatic filarial parasites on a geographic scale.

The genetic variation of filarial parasites is an important factor that may influence the efficacy of the drug as well as the development and spread of drug resistance among parasite populations (Anderson \& Jaenike 1997).

Financial support: LFSC, ICMR

$\mathrm{RD}$ is a recipient from CSIR-JRF.

+ Corresponding author: slhoti@yahoo.com

Received 30 July 2010

Accepted 16 December 2010
The issue of resistance to anthelmintics used for treating human helminth infections has become increasingly important (McCarthy 2005). It is well-known that parasite control programmes that rely on MDA are vulnerable to the development of drug resistance. This phenomenon is illustrated in humans by the spread of resistance of malaria to anti-malarial drugs, including chloroquine and pyrimethamine-sulfadoxine (Sibley et al. 2001) and in livestock by widespread anthelmintic resistance of parasitic nematodes to benzimidazoles (Wolstenholme et al. 2004). The presence of drug-resistant alleles for ALB in untreated populations of $W$. bancrofti has been demonstrated by a study carried out by Schwab et al. (2005). However, there is no record of resistance to DEC by $W$. bancrofti so far. The global programme employing MDA of DEC/IVM with ALB to eliminate LF is implemented in large areas of endemic countries. As population groups and the duration of the programme increase, the threat of failure due to resistance to the MDA may become more apparent. Hence, there is a need to understand the dynamics of the genetic structure of $W$. bancrofti populations in relation to the drug pressures applied. Therefore, the objective of this study was to understand the influence of anti-filarial chemotherapy on the genetic diversity $(\mathrm{H})$ and population structure of $W$. bancrofti, the major cause of LF in India. Since specific molecular markers that can differentiate the populations of $W$. bancrofti are not available, randomly amplified polymorphic DNA (RAPD) markers were employed to generate the genetic profiles of the parasite populations. RAPD does not require prior knowledge of the sequence data or large quantities of DNA and it yields high frequencies of polymorphic bands (Williams et al. 1990). It is also rapid and easy to perform, although the repro- 
ducibility depends on choosing the right primer(s). An earlier study reported that a suitable marker for studying the Hof $W$. bancrofti was identified by analysis of a panel of amplified fragment length polymorphism and RAPD markers (Thangadurai et al. 2006, Patra et al. 2007, Nath et al. 2010). Microfilariae (Mf) of $W$. bancrofti isolated from archived slides (Bisht et al. 2006) collected from areas under different chemotherapy strategies were used to determine the genetic parameters and analyze the Hand structure of the parasite populations from the different areas. The findings of this study are presented here.

\section{SUBJECTS, MATERIALS AND METHODS}

Study area and sample collection - A total of 178 populations of $W$. bancrofti were collected as blood smears from Mf carriers residing in two different states of India (Tamil Nadu, from the South, and Orissa, from the Central region) and were used for the study (Fig. 1, Table I). These states are located on the east coast of India and are separated from each other by approximately $2000 \mathrm{~km}$. Blood smears were collected from microfilaria carriers residing in the district of Thiruvannamalai (who were treated with MDA with DEC) and district of Thanjavur (who were treated with MDA with DEC + ALB), Tamil Nadu in 2003, after the launch of the LF elimination programme. Blood smears were collected during 1995 from different locations of Orissa from patients who were treated with selective therapy (ST) with DEC alone.

Parasite purification and DNA extraction - Microfilaria from each slide were counted and recorded before parasite purification. Five Mf from the dried blood smears were isolated using the protocol implemented by Bisht et al. (2006). DNA was extracted from $W$. bancrofti parasites by digesting the parasite in a buffer containing $50 \mathrm{mM}$ Tris- $\mathrm{HCl}$ ( $\mathrm{pH} 8.0$ ), $100 \mathrm{mM} \mathrm{NaCl}, 20 \mathrm{mM}$ ethylenediamine tetraacetic acid (EDTA), $1 \mathrm{mg} / \mathrm{mL}$ proteinase $\mathrm{K}$ and $1 \%$ sodium dodecyl sulphate at $56^{\circ} \mathrm{C}$ overnight (Hoti et al. 2003), followed by the standard phenol chloroform extraction (Sambrook et al. 1989). Genomic DNA was extracted and stored at $-20^{\circ} \mathrm{C}$ until use.
RAPD polymerase chain reaction (PCR) - RAPD PCR was carried out with random oligonucleotide primer-1 (Amersham-Pharmacia, Piscataway, New Jersey, USA). Amplification was performed in a thermal cycler (BioRad, USA) in a reaction volume of $30 \mu \mathrm{L}$ containing $3 \mu \mathrm{L} 10 \mathrm{x}$ buffer, $1 \mu \mathrm{L}$ of $50 \mathrm{mM} \mathrm{MgCl}, 0.2 \mathrm{mM}$ of each dNTP, 50 pmole of primer, 4 U DyNAzyme (Finnzymes, Finland) and approximately $50 \mathrm{ng}$ of extracted DNA. The thermal profile used was an initial denaturation of $94^{\circ} \mathrm{C}$ for $5 \mathrm{~min}$ followed by 39 cycles involving denaturation at $94^{\circ} \mathrm{C}$ for $1 \mathrm{~min}$, primer annealing at $40^{\circ} \mathrm{C}$ for

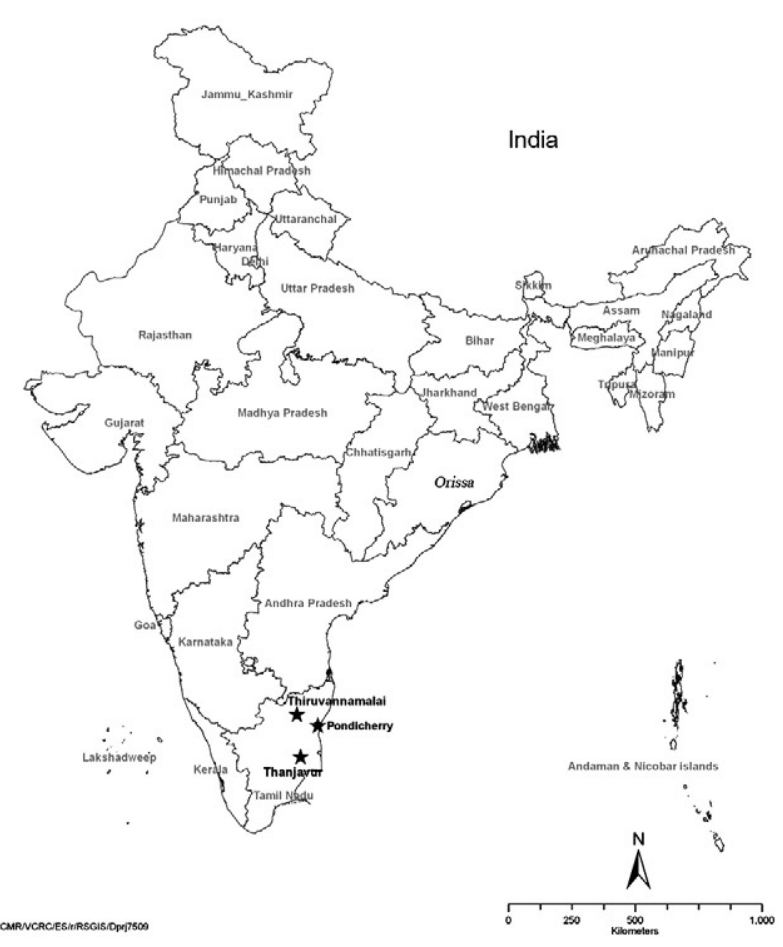

Fig. 1: map of India showing location of blood sample collection.

TABLE I

Genetic parameters generated from the randomly amplified polymorphic DNA (RAPD) profiles of microfilariae of Wuchereria bancrofti collected from areas with different chemotherapy strategies

\begin{tabular}{|c|c|c|c|c|c|c|c|c|}
\hline \multirow[b]{2}{*}{ Strategy } & \multirow[b]{2}{*}{ Area } & \multirow{2}{*}{$\begin{array}{l}\text { Population } \\
\text { size }\end{array}$} & \multicolumn{2}{|c|}{ Polymorphic loci } & \multirow{2}{*}{$\begin{array}{l}\text { Neis's gene } \\
\text { diversity }^{a}\end{array}$} & \multirow{2}{*}{$\begin{array}{l}\text { Shannon's } \\
\text { information } \\
\text { index }^{b}\end{array}$} & \multirow[b]{2}{*}{ Gst } & \multirow[b]{2}{*}{ Genetic distance } \\
\hline & & & $\mathrm{n}$ & $\%$ & & & & \\
\hline MDA - DEC & Thiruvannamalai & 74 & 74 & 100 & $0.2197 \pm 0.0076$ & $0.3710 \pm 0.1148$ & 0.3207 & $0.0000-0.4329$ \\
\hline $\begin{array}{l}\text { MDA } \\
\mathrm{DEC}+\mathrm{ALB}\end{array}$ & Thanjavure & 60 & 18 & 70.83 & $0.2317 \pm 0.0359$ & $0.3535 \pm 0.2657$ & 0.0856 & $0.0000-0.6131$ \\
\hline $\begin{array}{l}\text { ST } \\
\text { DEC }\end{array}$ & Orissa & 34 & 47 & 92.16 & $0.2660 \pm 0.0208$ & $0.4170 \pm 0.1934$ & 0.2662 & $0.1032-0.5996$ \\
\hline
\end{tabular}

$a$ : proportion of polymorphic loci across the genome; $b$ : measure of genetic differentiation; ALB: albendazole; DEC: diethylcarbamazine; genetic distance: a measure of the allelic substitutions per locus that have occurred during the separate evolution of two populations or species. This measure assumes that genetic differences arise to mutations and genetic drift; Gst: genetic differentiation across populations; MDA: mass drug administration; ST: selective therapy. 
$1 \mathrm{~min}$, extension at $72^{\circ} \mathrm{C}$ for $1 \mathrm{~min}$ and a final extension of $72^{\circ} \mathrm{C}$ for $8 \mathrm{~min}$. After amplification, $10 \mu \mathrm{L}$ of the PCR product was visualized with ethidium bromide staining after electrophoresis on a 1\% agarose/tris-acetate-EDTA gel using a transilluminator.

Data analysis - RAPD profiles generated were subjected to phylogenetic analyzes between individuals and groups of $W$. bancrofti populations by the unweighted pair group method with arithmetic means (UPGMA) after plotting Nei's unbiased genetic distance matrix (Nei 1978) using the PopGene 32 software (Yeh \& Rong-cai 1999). The genetic diversity (Nei 1978) and gene flow $[\mathrm{Nm}=0.5$ (1-Gst)/Gst] (McDermott \& McDonald 1993) among the individual populations, as well as among groups of parasite populations, were estimated to understand the variability in the overall population. UPGMA was employed to generate the dendrogram.

\section{RESULTS}

RAPD profiles were generated for all the parasite populations of $W$. bancrofti using a random primer that was previously used for studying genetic diversity of this parasite (Pradeep Kumar et al. 2002, Thangadurai et al. 2006, Dhamodharan et al. 2008). The size of the RAPD amplicons of $W$. bancrofti populations from Thiuvannamalai, Thanjavur and different locations of Orissa ranged between 110-2990 bp, 100-3000 bp and 146-2960 $\mathrm{bp}$, respectively (data not shown).

Genetic diversity and structure of $W$. bancrofti populations under MDA with DEC (Thiruvannamalai, Tamil $N a d u$ ) - Seventy-four populations of $W$. bancrofti from Thiruvannamalai, where MDA with DEC alone was implemented, were analyzed by generating RAPD profiles (Fig. 2). There were 74 polymorphic loci among the 74 parasite populations and the percentage of polymorphisms was $100 \%$. The mean genetic diversity was 0.2197 and the Nei's genetic distance ranged from 0.00.4329 (Fig. 3, Table I). Based on Nei's genetic distance, a dendrogram was generated using the UPGMA method. The dendrogram presented a complex picture, showing high levels of genetic diversity and a complex genetic structure in the parasite populations. The parasite populations formed several clusters of higher and lower levels, which could be clustered into eight groups (leaving

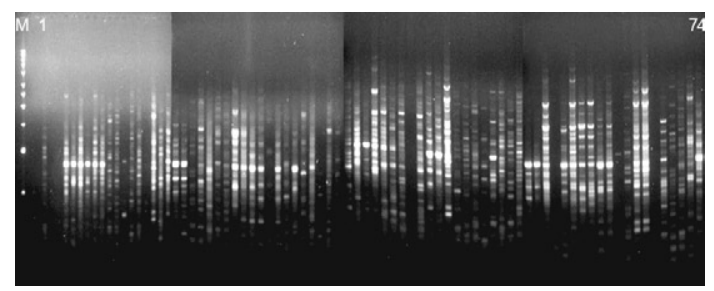

Fig. 2: randomly amplified polymorphic DNA profile of Wuchereria bancrofti microfilariae populations collected from carriers residing in district of Thiruvannamalai, state of Tamil Nadu, where mass drug administration with diethylcarbamazine alone was administered. Lanes 1-74: parasite isolates. M-I kb ladder. out basal single populations, pop 70) (Fig. 4). The genetic distance between these groups of parasite populations ranged from 0.0269-0.0901 (Table IIA). The genetic distance within group ranged from $0.1503-0.2252$, showing that groups of parasite populations exhibited low level of gene diversity. The overall gene flow among the eight groups was 2.2922 .

Genetic diversity and structure of $W$. bancrofti populations under MDA with DEC + ALB (Thanjavur, Tamil Nadu) - RAPD profiles were generated for $60 \mathrm{~W}$. bancrofti parasite populations from Thanjavur, where a combination of DEC and ALB was administered under MDA. There were 18 polymorphic loci and $70.83 \%$ polymorphisms in the 60 parasite populations. The mean genetic diversity among the population was 0.2317 and Nei’s genetic distance ranged from 0.0-0.6131 (Table I).

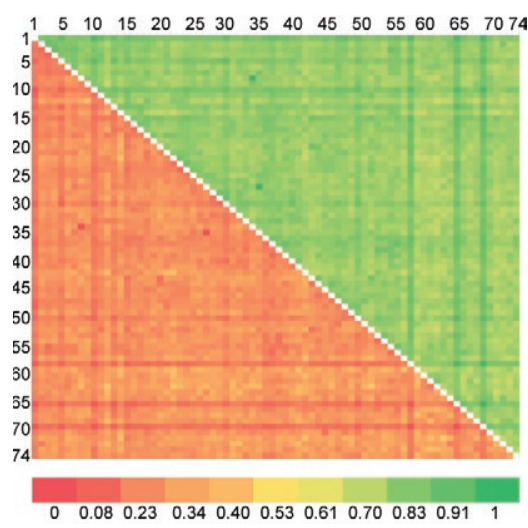

Fig. 3: Nei's genetic distance (below diagonal) and genetic identity (above diagonal) between 74 Wuchereria bancrofti populations from district of Thiruvannamalai, state of Tamil Nadu, where mass drug administration with diethylcarbamazine was administered.

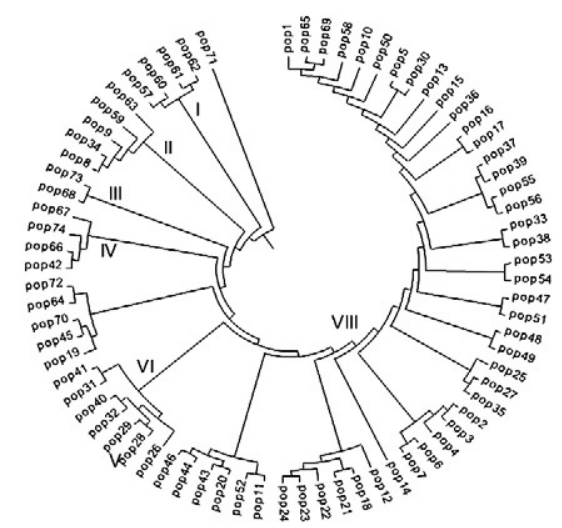

Fig. 4: dendrogram constructed based on Nei's genetic distance (unweighted pair group method with arithmetic means method) for the 74 parasite populations of Wuchereria bancrofti from district of Thiruvannamalai, state of Tamil Nadu, where mass annual drug administration with diethylcarbamazine alone was administered. Roman numerals indicate the cluster number. 
The topology of the constructed dendrogram showed five clusters (clusters I-V) (Fig. 5) with the majority of parasite populations falling under cluster $\mathrm{V}$, which further branched into two sub-clusters. Cluster I formed the ancestor and comprised the least number of populations (only 2). The genetic diversity among the five groups of parasite populations ranged from $0.1190-0.2555$ and the genetic distance between the groups ranged from 0.0074-0.0855 (Fig. 6, Table IIB). The overall gene flow among the populations of five groups was 0.1638 .

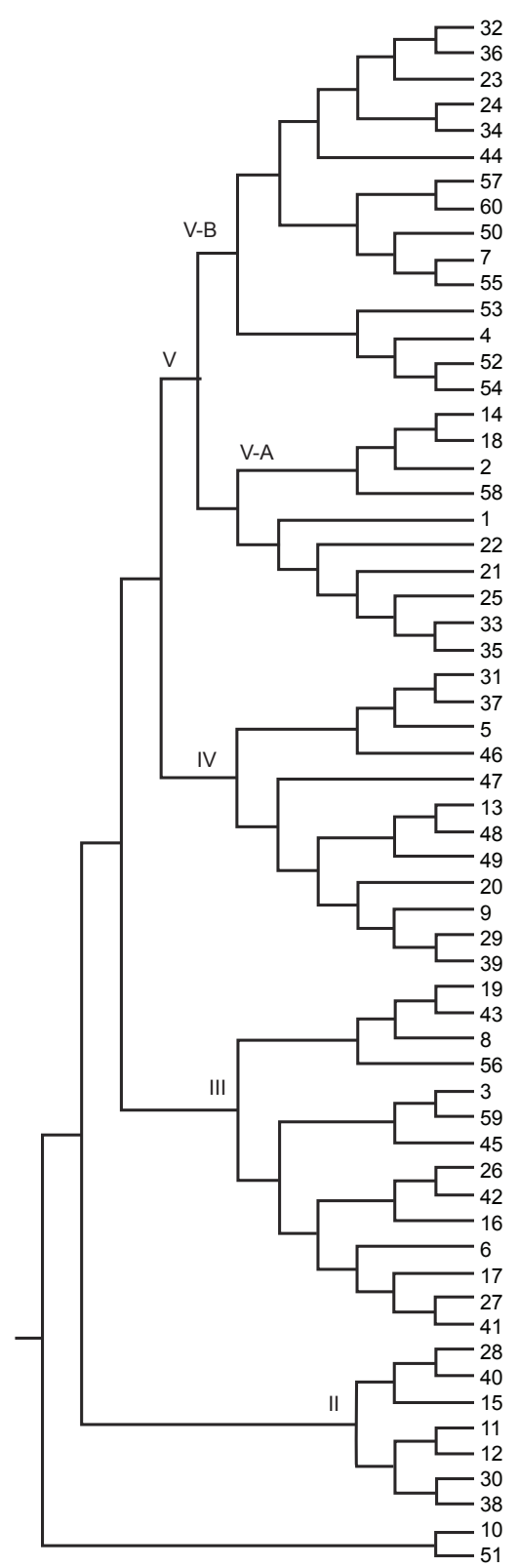

Fig. 5: dendrogram constructed based on Nei's genetic distance (unweighted pair group method with arithmetic means method) for the 60 parasite populations of Wuchereria bancrofti from district of Thanjavur, state of Tamil Nadu, where mass annual drug administration with a combination of diethylcarbamazine and albendazole was administered. Roman numerals indicate the cluster number.
Genetic diversity and structure of W. bancrofti populations under selective chemotherapy with DEC (Orissa) - Genetic diversity was analyzed for $34 \mathrm{~W}$. bancrofti populations collected from different locations in Orissa (Table I), where selective treatment with a standard dose of DEC has been in place for more than half a century. The number and percentage of polymorphic loci was 47 and 92.16, respectively. The mean genetic diversity among the populations was 0.2660 and the mean genetic distance ranged from 0.1032-0.5996 (Fig. 7, Table I). The phylogenetic tree constructed for the 34 parasite populations from different locations exhibited four groups, with the highest number of populations (17) falling under group 4 (Fig. 8). The mean genetic diversity within different groups ranged from 0.1863-0.2589 and the genetic distance ranged from 0.0053-0.1285 (Table IIC). The overall gene flow among the four groups of the populations was 1.8752 .

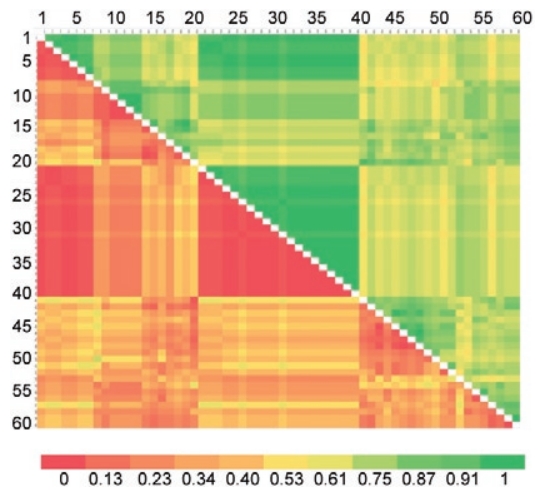

Fig. 6: Nei's genetic distance (below diagonal) and genetic identity (above diagonal) between 60 Wuchereria bancrofti populations from district of Thanjavur, state of Tamil Nadu, where mass drug administration with combination of diethylcarbamazine and albendazole was administered.

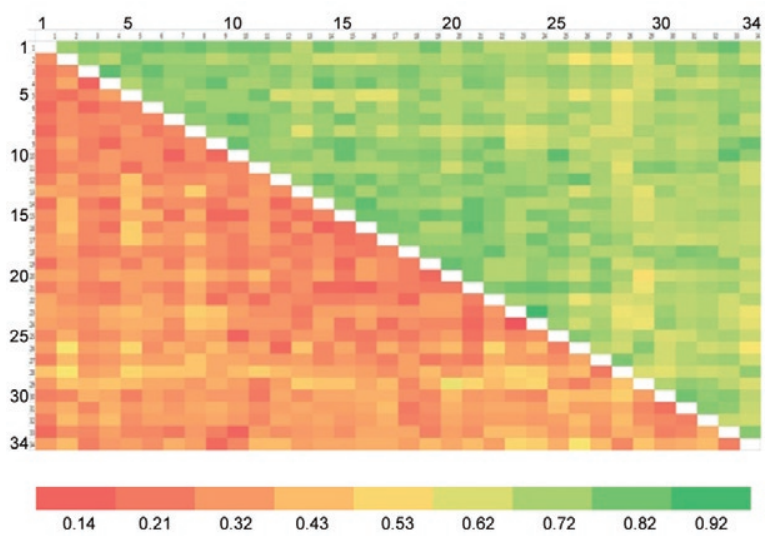

Fig. 7: genetic distance (below diagonal) and genetic identity (above diagonal) among 34 Wuchereria bancrofti populations from state of Orissa where selective therapy with diethylcarbamazine alone was administered. 
TABLE II

Genetic distance and genetic identity among groups of Wuchereria bancrofti based on cluster structure (Figs 4-6)

A: district of Thirvuannamalai, state of Tamil Nadu

\begin{tabular}{ccccccccc}
\hline Groups & 1 & 2 & 3 & 4 & 5 & 6 & 7 & 8 \\
\hline 1 & - & 0.9379 & 0.9242 & 0.9366 & 0.9142 & 0.95 & 0.9183 & 0.9475 \\
2 & 0.0641 & - & 0.9404 & 0.9599 & 0.9397 & 0.9607 & 0.9486 & 0.9706 \\
3 & 0.0788 & 0.0614 & - & 0.9293 & 0.9138 & 0.9438 & 0.9212 & 0.9552 \\
4 & 0.0654 & 0.041 & 0.0733 & - & 0.952 & 0.9594 & 0.9571 & 0.9735 \\
5 & 0.0897 & 0.0622 & 0.0901 & 0.0492 & - & 0.952 & 0.945 & 0.9646 \\
6 & 0.0513 & 0.0401 & 0.0579 & 0.0414 & 0.0492 & - & 0.9503 & 0.9712 \\
7 & 0.0853 & 0.0528 & 0.0821 & 0.0439 & 0.0565 & 0.0509 & - & 0.9697 \\
8 & 0.054 & 0.0299 & 0.0458 & 0.0269 & 0.036 & 0.0293 & 0.0307 & -
\end{tabular}

0.1503-0.2252: genetic diversity range among groups of parasite population; 2.2922: over all gene flow among groups.

B: district of Thanjavur, state of Tamil Nadu

\begin{tabular}{cccccc}
\hline Groups & 1 & 2 & 3 & 4 & 5 \\
\hline 1 & - & 0.918 & 0.9683 & 0.9464 & 0.9268 \\
2 & 0.0855 & - & 0.9491 & 0.9735 & 0.9921 \\
3 & 0.0322 & 0.0522 & - & 0.9926 & 0.9771 \\
4 & 0.0551 & 0.0269 & 0.0074 & - & 0.9878 \\
5 & 0.076 & 0.008 & 0.0232 & 0.0123 & -
\end{tabular}

0.1190-0.2555: genetic diversity range among groups of parasite population; 0.1638: over all gene flow among groups.

C: state of Orissa

\begin{tabular}{ccccc}
\hline Groups & 1 & 2 & 3 & 4 \\
\hline 1 & - & 0.8899 & 0.8794 & 0.8988 \\
2 & 0.1167 & - & 0.9568 & 0.9799 \\
3 & 0.1285 & 0.0442 & - & 0.9947 \\
4 & 0.1067 & 0.0203 & 0.0053 & - \\
\hline
\end{tabular}

0.0053-0.1285: genetic diversity range among groups of parasite population; 1.8752: over all gene flow among groups. The relatedness of two populations as represented by percentage of allele they share.

\section{DISCUSSION}

The population genetic structure of most helminths remains largely unknown, but this knowledge is essential for predicting how fast phenotypes of interest, such as antigenic variants and drug resistance, originate and spread among populations (Zhong et al. 2007). Several pressures and forces operate in maintaining the genetic structure of parasite populations and changes in these pressures can influence the epidemiology of transmission of parasitic infections. The genetic structure of vector-borne parasite populations is influenced by mating success, population size, transmission intensity and natural selection, as well as by factors such as chemotherapy, vector control and environment. Apart from these influences, genetic factors such as mutation, intergenic recombination determined by multiplicity of host infections and gene flow between different populations can also influence population structures (Maizels \& Kurniawan-Atmadja 2002, de Souza-Neiras et al.
2007). Anti-parasite drug treatment will have especially profound influences on the genetic diversity and therefore the genetic structure of parasite populations (Grant 1994). In recent years, there has been a substantial increase in the use of MDA to reduce the morbidity associated with parasitic infections of humans (Lammie et al. 2006). Lymphatic filarial parasites are now under the pressures of MDA of a combination of anti-filarial drugs, such as DEC or IVM, and an anthelmintic drug, ALB. This strategy, aimed at interruption of transmission, could be the single most important factor influencing the genetic structure of $W$. bancrofti, which is the major target of the global elimination programme.

The present study was aimed at assessing the influence of different chemotherapy strategies regarding (i) the standard selective treatment with DEC, (ii) the annual single dose of MDA with DEC alone and (iii) the annual single dose of MDA with combination of DEC and ALB, on the genetic structure of $W$. bancrofti populations. The two MDA strategies were under trial pri- 


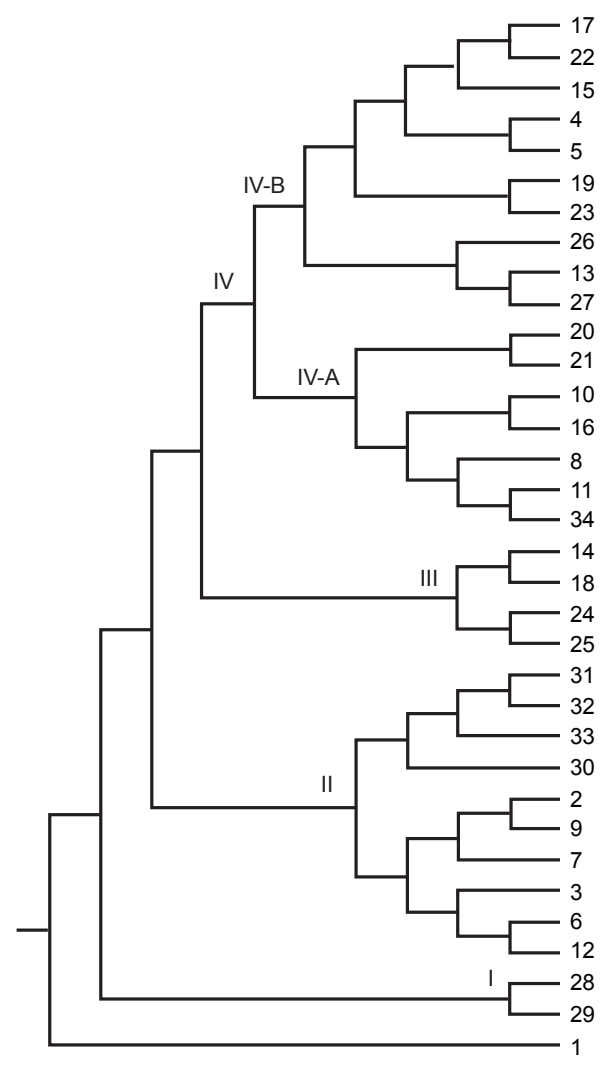

Fig. 8: dendrogram constructed based on Nei's genetic distance (unweighted pair group method with arithmetic means method) for the 34 parasite populations of Wuchereria bancrofti from different locations of state of Orissa, where selective therapy with diethylcarbamazine alone was administered. Roman numerals indicate the cluster number.

or to the launch of the global elimination programme, whereas the ST has been in place for almost half a century. RAPD was employed to assess the genetic structure of different populations, as this technique is able to distinguish between closely related individuals, which make it ideal for use if insufficient sequence information is available (Liu et al. 2004). An interesting technical component of the study is that the archived blood slides were utilized as the source of parasite (Mf) populations. These were collected and stored at room temperature during epidemiological and other surveys several years ago, employing a method developed earlier in our laboratory (Bisht et al. 2006).

The analysis of various genetic parameters for parasite populations under different chemotherapy strategies indicated that the influence of the chemotherapy strategies on the genetic structure of $W$. bancrofti populations varied with the strategy. Parasite populations from Orissa, where ST with a standard dose of DEC was in place for a long time, were more genetically diverse than the parasite populations from areas under MDA. These parasites had higher mean genetic diversity among than parasite populations under MDA with DEC alone or under co-administration of DEC with ALB. This indicates that the MDA reduces the genetic diversity of parasite populations, whereas ST maintains it. The sub-populations (groups) of $W$. bancrofti (as inferred from the dendrogram) from Orissa also exhibited high genetic diversity. W. bancrofti populations from the Thiruvannamalai area, which were under MDA with DEC alone, were less genetically diverse than those from Thanjavur that were under MDA with a combination of drugs. There are no studies available in the literature comparing the influence of different drug regimens on the genetic structure of nematode parasites. The mode of action and pharmacodynamic properties of the drugs, whether singly or in combination, may influence microfilarial genetic diversity for a number of years after chemotherapy (Ottesen et al. 2008). Whereas DEC acts through modulation of the immune system of the host (Denham et al. 1978), ALB acts by directly inhibiting the polymerization of the $\beta$-tubulin monomers of microtubules (Lacey 1988). Many studies have shown variation in the microfilaricidal and macrofilaricidal activity of DEC alone compared to combinations of DEC + ALB and DEC + IVM (Dreyer et al. 1998, 2006, Ramaiah et al. 2002, Florêncio \& Peixoto 2003, Hussein et al. 2004, Mak 2004, Critchley et al. 2005).

The genetic diversity of filarial parasites is expected to be maintained at high levels because of the genetic flux within the infrapopulation of filarial parasites. There is a constant influx of new infective stage larvae during the lifespan of a human host in an endemic area, adding to the existing genetic diversity of the infrapopulation, which is further facilitated by the long lifespan of adult parasites. The genetic diversity of filarial parasites is also maintained by the nature of their microhabitat, also known as the "worm nest" (Dreyer et al. 1994). The adult male and female parasites are confined throughout their lifespan within nests inside the host where they can mate and female worms can release embryonic stage parasites into the circulating blood. Anti-filarial treatment causes a major disturbance to this state of high diversity. Whereas administration of a complete dose of the drug [ST (6 mg/kg body weight for 12 days)] will maintain the genetic diversity of parasites, under-dosing, as in the case of MDA for LF elimination, partially effective drugs (currently available drugs are partially effective against adult parasites) or treatment drop-outs will reduce genetic diversity and hence may facilitate the selection of drug resistance alleles among parasite populations (Paul et al. 1995, White 2005). Combined treatment with IVM and ALB could be expected to reduce the rate of selection for resistance to either of these anthelmintics. Eng et al. (2006) showed that IVM acts on $\beta$-tubulin in the filarial nematode Onchocerca volvulus. Although they observed that IVM selection was not associated with changes in the Phe200Tyr amino acid, selection by two anthelmintics can involve the same gene.

This limited scale study indicated that MDA strategies may influence the genetic structure of $W$. bancroft $i$ populations. However, systematic and large-scale population genetic studies need to be carried out, preferably after each round of MDA, to assess and predict the influence of the MDA strategy on the genetic structure of these parasites. 
Recently, a study by Schwab et al. (2005) showed that two rounds of MDA with ALB + IVM led to increases in the putative alleles implicated in resistance to ALB, indicating that the genetic diversity of $W$. bancrofti was influenced by MDA. The present study is a preliminary investigation and was carried out with parasite material collected for different purposes; therefore, it suffers from a lack of systematic sampling and adequate time scales. However, it will pave the way for larger and more systematic studies. Two of the techniques developed in our laboratory, isolation of Mf from archived blood slides (Bisht et al. 2006) and isolation of Mf from blood clots that are discarded after separating serum (Hoti et al. 2008), made the study more feasible because they allowed for obtaining the parasite material for population genetic studies with ease.

\section{ACKNOWLEDGEMENTS}

To Dr P Jambulingam, director, and Dr PK Das, former director, for their continuous support and suggestions, and to Drs SP Pani and K Krishnamoorthy, scientist F, for providing the microfilariae positive slides.

\section{REFERENCES}

Anderson TJ, Jaenike J 1997. Host specificity, evolutionary relationships and macrogeographic differentiation among Ascaris populations from humans and pigs. Parasitology 115: 325-342.

Bisht R, Hoti SL, Thangadurai R, Das PK 2006. Isolation of Wuchereria bancrofti microfilariae from archived stained blood slides for use in genetic studies and amplification of parasite and endosymbiont genes. Acta Trop 99: 1-5.

Critchley J, Addiss D, Gamble C, Garner P, Gelband H, Ejere H 2005. Albendazole for lymphatic filariasis. Cochrane Database Syst Rev 4: CD003753.

de Souza-Neiras WC, de Melo LMS, Machado RLD 2007. The genetic diversity of Plasmodium vivax - A review. Mem Inst Oswaldo Cruz 102: 245-254.

Denham DA, Suswillo RR, Rogers R, McGreevy PB 1978. Studies with Brugia pahangi 17. The anthelmintic effects of diethylcarbamazine. J Parasitol 64: 463-468.

Dhamodharan R, Das MK, Hoti SL, Das PK, Dash AP 2008. Genetic variability of diurnally sub-periodic Wuchereria bancrofti in Nicobarese tribe of Nicobar group of Islands, Andaman and Nicobar Islands, India. Parasitol Res 103: 59-66.

Dreyer G, Addiss D, Santos A, Figueredo-Silva J, Norões J 1998. Direct assessment in vivo of the efficacy of combined single-dose ivermectin and diethylcarbamazine against adult Wuchereria bancrofti. Trans R Soc Trop Med Hyg 92: 219-222.

Dreyer G, Addiss D, Williamson J, Norões J 2006. Efficacy of coadministered diethylcarbamazine and albendazole against adult Wuchereria bancrofti. Trans R Soc Trop Med Hyg 100: 1118-1125.

Dreyer G, Amaral F, Norões J, Medeiros Z 1994. Ultrasonographic evidence for stability of adult worm location in bancroftian filariasis. Trans R Soc Trop Med Hyg 88: 558.

Eberhard ML, Lammie PJ, Dickinson CM, Roberts JM 1991. Evidence of nonsusceptibility to diethylcarbamazine in Wuchereria bancrofti. J Infect Dis 163: 1157-1160.

Eng JK, Blackhall WJ, Osei-Atweneboana MY, Bourguinat C, Galazzo D, Beech RN, Unnasch TR, Awadzi K, Lubega GW, Prichard RK 2006. Ivermectin selection on beta-tubulin: evidence in $\mathrm{On}$ - chocerca volvulus and Haemonchus contortus. Mol Biochem Parasitol 150: 229-235.

Florêncio MS, Peixoto CA 2003. The effects of diethylcarbamazine on the ultrastructure of microfilariae of Wuchereria bancrofti. Parasitology 126: 551-554.

Yeh FC, Rong-cai Y 1999. Popgene v.1.31 Microsoft Windows-based freeware for population genetic analysis.

Grant WN 1994. Genetic variation in parasitic nematodes and its implications. Int J Parasitol 24: 821-830.

Hoti SL, Subramaniyan K, Das PK 2003. Detection of codon for amino acid 200 in isotype 1 beta-tubulin gene of Wuchereria bancrofti isolates, implicated in resistance to benzimidazoles in other nematodes. Acta Trop 88: 77-81.

Hoti SL, Sharma R, Mary KA, Dhamodharan R, Krishnamoorthy K, Das PK 2008. A method for detecting microfilaraemia, filarial specific antigens and antibodies and typing of parasites for drug resistance and genotypes using finger prick blood sample. Acta Trop 107: 268-271.

Hussein O, El Setouhy M, Ahmed ES, Kandil AM, Ramzy RM, Helmy H, Weil GJ 2004. Duplex doppler sonographic assessment of the effects of diethylcarbamazine and albendazole therapy on adult filarial worms and adjacent host tissues in Bancroftian filariasis. Am J Trop Med Hyg 71: 471-477.

Lacey E 1988. The role of the cytoskeletal protein, tubulin, in the mode of action and mechanism of drug resistance to benzimidazoles. Int J Parasitol 18: 885-936.

Lammie PJ, Fenwick A, Utzinger J 2006. A blueprint for success: integration of neglected tropical disease control programmes. Trends Parasitol 22: 313-321.

Liu G, Tao CM, Zhai CY 2004. Application of M-RAPD technique to obtain the genomic fingerprints of various pathogenic microbials. Sichuan Da Xue Xue Bao Yi Xue Ban 35: 563-567.

Maizels RM, Kurniawan-Atmadja A 2002. Variation and polymorphism in helminth parasites. Parasitology 125 (Suppl.): S25-37.

Mak JW 2004. Antifilarial compounds in the treatment and control of lymphatic filariasis. Trop Biomed 21: 27-38.

McCarthy J 2005. Is anthelmintic resistance a threat to the program to eliminate lymphatic filariasis? Am J Trop Med Hyg 73: 232-233.

McDermott JM, McDonald BA 1993. Gene flow in plant pathosystem. Ann Rev Phytopathol 31: 353-373.

Nath G, Maurya P, Gulati AK 2010. ERIC PCR and RAPD based fingerprinting of Salmonella typhi strains isolated over a period of two decades. Infect Genet Evol 10: 530-536.

Nei M 1978. Analysis of gene diversity in subdivided populations. Proc Nat Acad Sci USA 70: 3321-3323.

Ottesen EA, Hooper PJ, Bradley M, Biswas G 2008. The global programme to eliminate lymphatic filariasis: health impact after 8 years. PLoS Negl Trop Dis 2: e317.

Patra KP, Ramu T, Hoti SL, Pragasam GS, Das PK 2007. Identification of a molecular marker for genotyping human lymphatic filarial nematode parasite Wuchereria bancrofti. Exp Parasitol 116: 59-65.

Paul RE, Packer MJ, Walmsley M, Lagog M, Ranford-Cartwright LC, Paru R, Day KP 1995. Mating patterns in malaria parasite populations of Papua New Guinea. Science 269: 1709-1711.

Pradeep Kumar N, Patra KP, Hoti SL, Das PK 2002. Genetic variability of the human filarial parasite, Wuchereria bancrofti in South India. Acta Trop 82: 67-76. 
Ramaiah KD, Vanamail P, Pani SP, Yuvaraj J, Das PK 2002. The effect of six rounds of single dose mass treatment with diethylcarbamazine or ivermectin on Wuchereria bancrofti infection and its implications for lymphatic filariasis elimination. Trop Med Int Health 7: 767-774.

Sambrook J, Fritsch EF, Maniatis T 1989. Molecular cloning: a laboratory manual, 2nd ed., Cold Spring Harbor Laboratory Press, New York, p. E3-E4.

Schwab AE, Boakye DA, Kyelem D, Prichard RK 2005. Detection of benzimidazole resistance-associated mutations in the filarial nematode Wuchereria bancrofti and evidence for selection by albendazole and ivermectin combination treatment. Am J Trop Med Hyg 73: 234-238.

Sibley CH, Hyde JE, Sims PF, Plowe CV, Kublin JG, Mberu EK, Cowman AF, Winstanley PA, Watkins WM, Nzila AM 2001. Pyrimethamine-sulfadoxine resistance in Plasmodium falciparum: what next? Trends Parasitol 17: 582-588.
Thangadurai R, Hoti SL, Kumar NP, Das PK 2006. Phylogeography of human lymphatic filarial parasite, Wuchereria bancrofti in India. Acta Trop 98: 297-304.

White NJ 2005. Intermittent presumptive treatment for malaria. PLoS Med 2: e3.

WHO - World Health Organization 2002. Elimination of lymphatic filariasis. Wkly Epidemiol Rec 77: 177-179.

Williams JG, Kubelik AR, Livak KJ, Rafalski JA, Tingey SV 1990. DNA polymorphisms amplified by arbitrary primers are useful as genetic markers. Nucleic Acids Res 18: 6531-6535.

Wolstenholme AJ, Fairweather I, Prichard R, von Samson-Himmelstjerna G, Sangster NC 2004. Drug resistance in veterinary helminths. Trends Parasitol 20: 469-476.

Zhong D, Afrane Y, Githeko A, Yang Z, Cui L, Menge DM, Temu EA, Yan G 2007. Plasmodium falciparum genetic diversity in western Kenya highlands. Am J Trop Med Hyg 77: 1043-1050. 